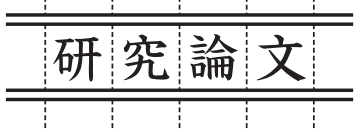

\author{
研究室規模の加圧流動層燃焼炉による \\ 下水污泥の排ガス特性に及ぼす圧力の影響
}

\title{
Effect of Operating Pressure on Flue Gas Characteristics of Sewage Sludge in a Laboratory-scale Pressurized Fluidized Bed Combustor
}

\author{
村上高広*・鈴木善三* \\ Takahiro MURAKAMI and Yoshizo SUZUKI
}

(Received September 18, 2009)

\begin{abstract}
Annual production of sewage sludge in Japan increased to 2.17 million tons (d.b.) in 2004. About $70 \%$ of sewage sludge is incinerated. The nitrogen content of the sludge is considerably higher than that of other fuels, such as coal and wood. Thus the emissions of $\mathrm{NO}_{\mathrm{x}}$ and $\mathrm{N}_{2} \mathrm{O}$ are anticipated to be high. Our previous studies have been reported the proposed fluidized bed incinerator with the turbocharger (FBIT), which is a new type of incineration plant consisting of a pressurized fluidized bed combustor coupled with a turbocharger, can achieve not only energy recovery but also a low environmental impact. The objectives of this work were to clarify the effect of wide range of operating pressure on flue gas characteristics in a laboratory-scale pressurized fluidized bed combustor (PFBC). As the results, $\mathrm{CO}$ and $\mathrm{NO}_{\mathrm{x}}$ emissions depend on the pressure in the combustor, and these emissions decreased with increasing operating pressure. $\mathrm{N}_{2} \mathrm{O}$ emission was strongly depended on the freeboard temperature in the combustor.
\end{abstract}

Key Words: Sewage Sludge, Pressurized Fluidized Bed Combustor, Flue Gas Characteristics, $\mathrm{NO}_{\mathrm{x}}, \mathrm{N}_{2} \mathrm{O}$

\section{1. 緒 言}

これまでに、下水污泥を燃料として用い、燃焼炉を加圧 流動層とし、その後段に過給機を設置して、排ガスにより それを駆動させることで然焼空気を生成させる過給式流動 炉システムの燃焼特性について報告した ${ }^{1)}$ 。本報では、加 圧流動層燃焼炉に着目し、下水污泥の排ガス特性に及ぼす 圧力の影響について実験的に検討した結果を報告する。

\section{2. 実験装置および方法}

Fig. 1 に加圧流動層燃焼システムの全体構成を示す。本

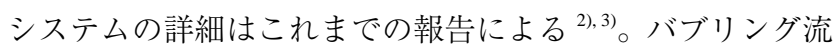
動層燃焼炉（Fig. 2）を加圧容器（Fig. 3）内に設置し、コ ンプレッサーで製造された加圧空気を、本容器内へ所定の 圧力条件になるまで供給した。流動層実験装置内の空気量 を計測するために、その配管を一旦容器外に導き、マスフ ローメーターで計量した後、再び容器内に戻し、装置下部 へ接続して供給する構造とした。運転中の温度は、熱電対 により砂層内（ $\left.\mathrm{T}_{\mathrm{b} 1}: 50 \mathrm{~mm}, \mathrm{~T}_{\mathrm{b} 2}: 300 \mathrm{~mm}\right)$ およびフリーボ ード $\left(\mathrm{T}_{\mathrm{fb} 1}: 800 \mathrm{~mm}, \mathrm{~T}_{\mathrm{fb} 2}: 1200 \mathrm{~mm}\right)$ で各 2 点測定した（括 弧内の数值は分散板からの距離を示す)。燃料はモーノポ

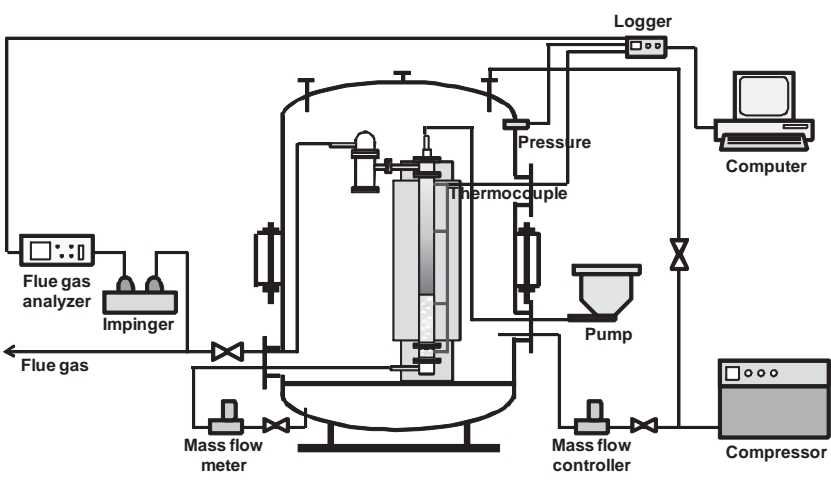

Fig. 1 Schematic diagram of a lab-scale PFBC system.

ンプにより、所定温度に到達後、装置最上部の垂直投入管 より連続供給した。流動媒体には 7 号硅砂（平均粒径：約 $0.24 \mathrm{~mm}$ ）を使用し、静止層高で $300 \mathrm{~mm}$ となるように充填 した。

実験方法として、燃料は実脱水污泥を使用した。操作 圧力は $0.2 、 0.3$ および $0.6 \mathrm{MPa}$ の 3 条件とした。砂層温度 1000 ～ 1200 K、流動条件は最小流動化速度の約 3 倍とした。

*(独) 産業技術総合研究所エネルギー技術研究部門クリーンガスグループ（テ $305-8569$ 茨城県つくば市小野川 16-1）

National Institute of Advanced Industrial Science and Technology (AIST),Energy Technology Research Institute, Clean Gas Group (16-1, Onogawa, Tsukuba, Ibaraki 305-8569, Japan) 


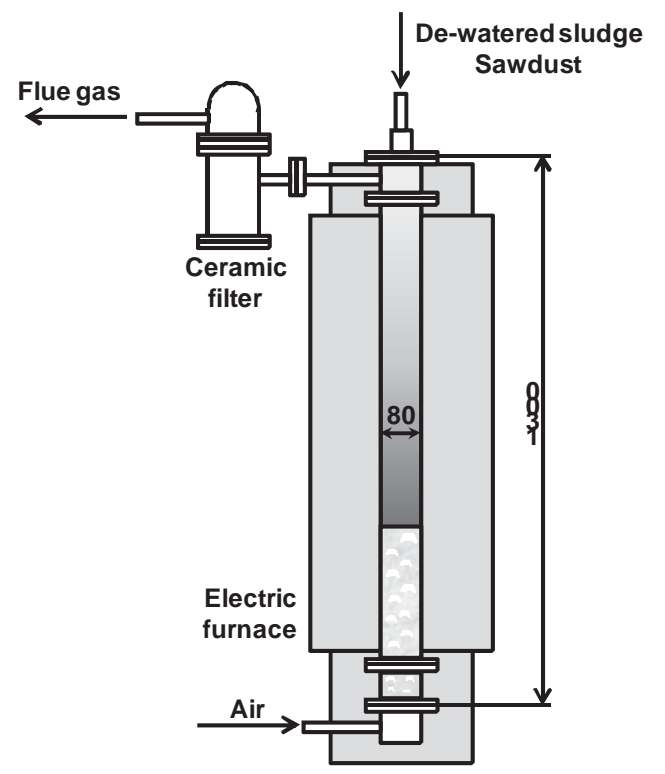

Fig. 2 Schematic diagram of a bubbling fluidized bed combustor.

Table 1 De-watered sludge properties

\begin{tabular}{|c|c|c|}
\hline \multicolumn{2}{|c|}{} & De-watered sludge \\
\hline \multirow{4}{*}{$\begin{array}{c}\text { Proximate } \\
\text { analysis } \\
\text { [dry, wt\%] }\end{array}$} & Moisture & 78.0 \\
\cline { 2 - 3 } & VM & 13.9 \\
\cline { 2 - 3 } & Ash & 1.8 \\
\hline \multirow{4}{*}{$\begin{array}{c}\text { Ultimate } \\
\text { analysis } \\
\text { [dry, wt\%] }\end{array}$} & $\mathrm{C}$ & 6.3 \\
\cline { 2 - 3 } & $\mathrm{H}$ & 29.8 \\
\cline { 2 - 3 } & Comb. S & 4.0 \\
\cline { 2 - 3 } & $\mathrm{O}$ & 5.0 \\
\hline \multirow{2}{*}{$\begin{array}{c}\text { Heating value (HHV) } \\
\text { [MJ/kg] (dry) }\end{array}$} & 1.1 \\
\hline
\end{tabular}

燃焼後の排ガスは、セラミックフィルタで脱塵し大気圧ま で減圧した後、ガス中の水蒸気をインピンジャーにより凝 縮除去させ、 $\mathrm{O}_{2} 、 \mathrm{CO} 、 \mathrm{CO}_{2}$ および $\mathrm{NO}$ は赤外線ガス分析計 (IR400、横河電機(株)）により分析し、 $\mathrm{N}_{2} \mathrm{O}$ はガスクロマト グラフ（G2891A, Hewlett Packard）により分析した。脱水 污泥の性状を Table 1 に示す。本表より、脱水污泥は可燃 分の約 $90 \mathrm{wt} \%$ が揮発分であり、乾燥ペースで、灰分は約 $30 \mathrm{wt} \%$ 、窒素分は $5.0 \mathrm{wt} \%$ と他の燃料よりも高いことが特 徵である。

\section{3. 実験結果および考察}

\section{$3.1 \mathrm{CO}$ 排出特性}

排ガス中の $\mathrm{CO}$ 濃度と $\mathrm{O}_{2}$ 濃度との関係を Fig. 4 に示す。

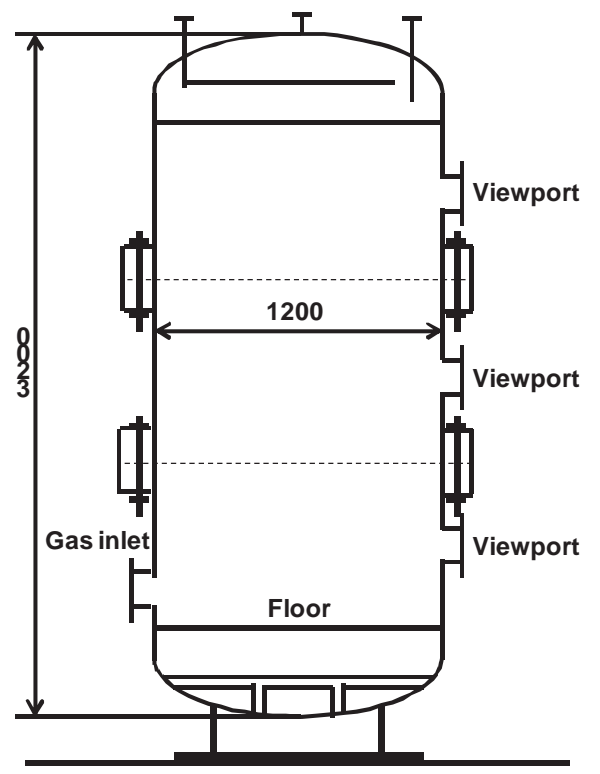

Fig. 3 Schematic diagram of a pressure vessel.

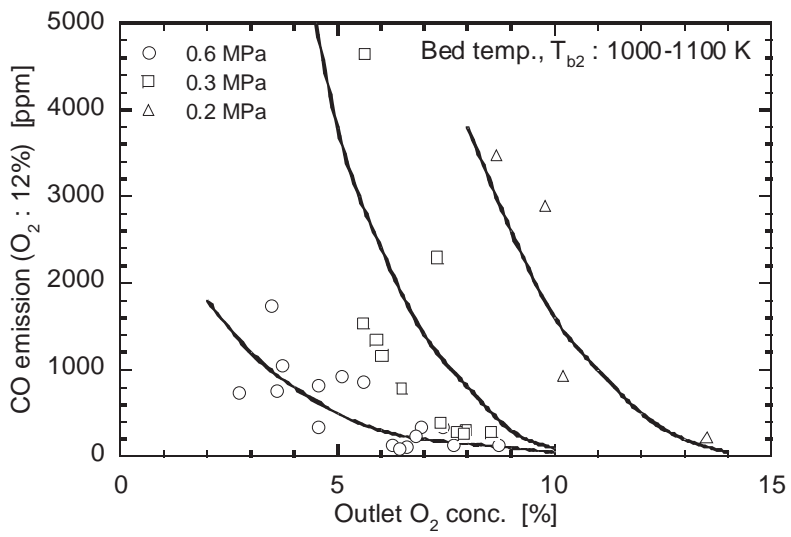

Fig. 4 Relationship between $\mathrm{CO}$ emission and $\mathrm{O}_{2}$ concentration in the flue gas.

砂層温度は 1000 〜 $1100 \mathrm{~K}$ で整理した。本図より、排ガス 中の $\mathrm{O}_{2}$ 濃度が高いほど $\mathrm{CO}$ 濃度は低くなり、燃焼が進行 しているといえる。また同じ $\mathrm{O}_{2}$ 濃度で比較すると、圧力 の依存性が明らかである。これは、圧力が高いほど然焼が 促進されるため CO 濃度は低くなるといえる。ただし、0.6 $\mathrm{MPa} 、 \mathrm{O}_{2}$ 濃度 : $5 \%$ の条件でも数百 $\mathrm{ppm}$ の CO 濃度が生成 しているが、これは本燃焼炉内のフリーボードでのガス滞 留時間が短いためであるといえる。

\section{$3.2 \mathrm{NO}_{\mathrm{x}}$ 生成特性}

排ガス中の $\mathrm{NO}_{\mathrm{x}}$ 濃度と $\mathrm{O}_{2}$ 濃度との関係を Fig. 5 に示す。 操作圧力：0.3 MPa で整理した。本図より、排ガス中の $\mathrm{O}_{2}$ 濃度が $5 \sim 7 \%$ の範囲で $\mathrm{NO}_{\mathrm{x}}$ 濃度は最小值となり、さらに $\mathrm{O}_{2}$ 濃度が低下すると $\mathrm{NO}_{\mathrm{x}}$ 濃度は増加した。本来 $\mathrm{O}_{2}$ 濃度が 


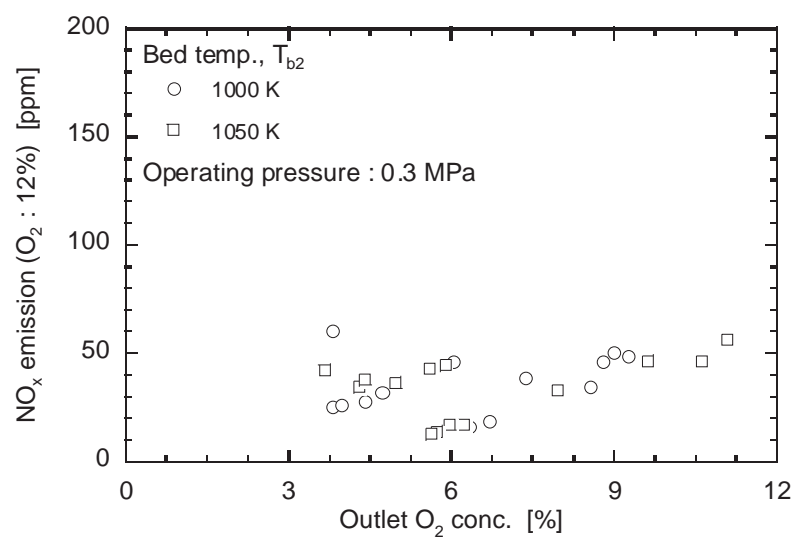

Fig. 5 Relationship between $\mathrm{NO}_{\mathrm{x}}$ emissions and $\mathrm{O}_{2}$ concentration in the flue gas.

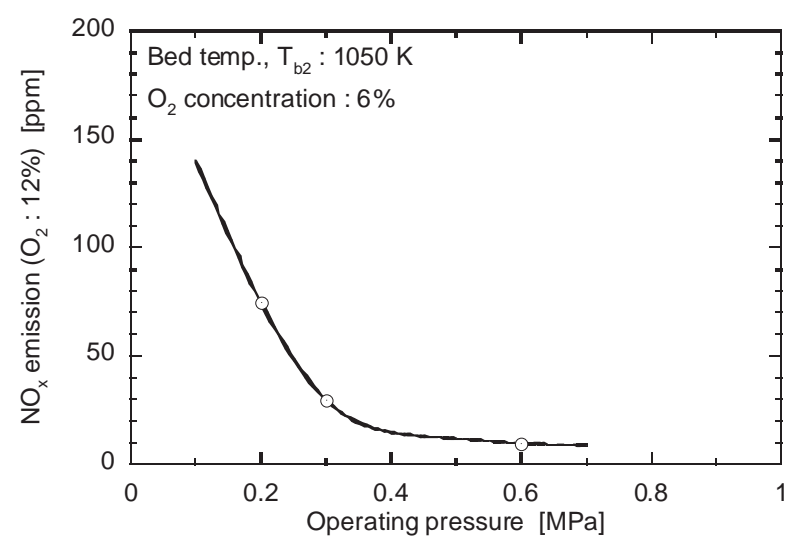

Fig. 6 Relationship between $\mathrm{NO}_{\mathrm{x}}$ emissions in the flue gas and operating pressure.

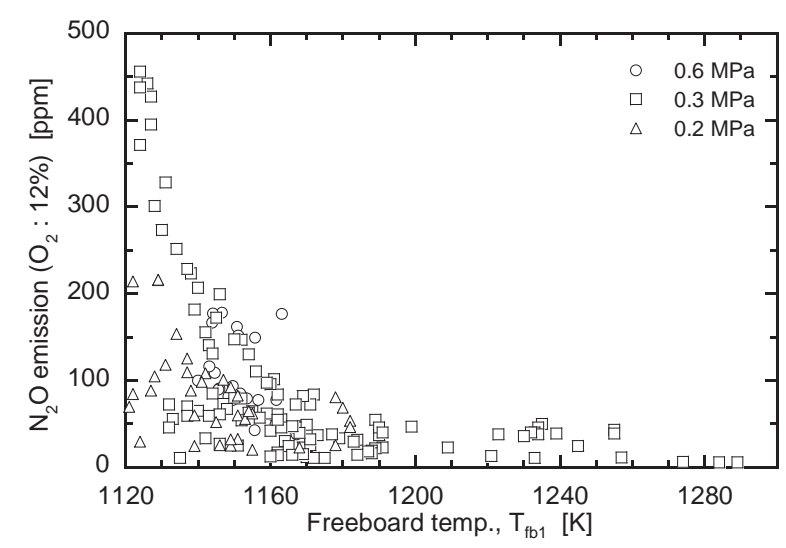

Fig. 7 Relationship between $\mathrm{N}_{2} \mathrm{O}$ emission and freeboard temperature.

増加するに連れて、 $\mathrm{NO}_{\mathrm{x}}$ 濃度は増加する傾向にあるが 本結果は逆の結果が得られた。さらに、石炭燃焼場での $\mathrm{NO}_{\mathrm{x}}$ 放出濃度よりも低濃度となった ${ }^{7-9)}$ 。污泥中の水分はと
ても高いため、Oラジカルや OH ラジカル濃度に影響を与 え、NO生成反応を抑制する効果がある ${ }^{10)}$ 。さらに、加圧 条件により水蒸気分圧が高くなるので、 $\mathrm{NO}_{x}$ 抑制効果も大 きくなると推測できる。

排ガス中の $\mathrm{NO}_{x}$ 濃度と圧力との関係を Fig. 6 に示す。本 図より、圧力の依存性が明らかであり、圧力が高くなるに 連れて、 $\mathrm{NO}_{x}$ 濃度は低くなっている。これは石炭燃焼の場 合と同じである ${ }^{11}$ 。石炭燃焼では、層内でチャーによる NO の還元効果があり、流動層内の圧力の個数密度が、圧 力が高くなるに連れて増大するためであると考えられる。 本研究で使用した揮発分の燃焼が主体である脱水污泥の燃 焼に扔いても、高水蒸気濃度による抑制効果に加え、この ような加圧の効果があるといえる。

\section{$3.3 \mathrm{~N}_{2} \mathrm{O}$ 生成特性}

排ガス中の $\mathrm{N}_{2} \mathrm{O}$ 濃度とフリーボード温度との関係を Fig. 7 に示す。本実験は、炉内の温度を電気炉により制御した ため、圧力条件が異なってもフリーボード温度の分布はほ ほ同等となるように制御した。本図より、 $\mathrm{NO}_{\mathrm{x}}-\mathrm{N}_{2} \mathrm{O}$ のトレ 一ドオフの関倸より、圧力が高くなるに連れて、 $\mathrm{N}_{2} \mathrm{O}$ 濃度 は高くなる傾向にあるが、フリーボード温度に強い依存性 を示した。フリーボード温度が高くなるに連れて、 $\mathrm{N}_{2} \mathrm{O}$ 濃 度は低くなっている。したがって、脱水污泥の燃焼では、 燃焼炉内のフリーボード温度で排ガス中の $\mathrm{N}_{2} \mathrm{O}$ 濃度を整理 できるといえる ${ }^{12), 133 。}$

今後、 $\mathrm{N}$ 分の素反応モデルを組み込んだシミュレーショ ンを実施することにより、 $\mathrm{NO}_{\mathrm{x}}$ 打よび $\mathrm{N}_{2} \mathrm{O}$ 排出特性におけ る圧力の影響を理論的に明らかにし、実験結果と比較・考 察する。

\section{4. 結 論}

研究室規模の加圧流動層燃焼炉により、下水污泥の排ガ ス特性における圧力の影響を明らかにした。得られた結果 を以下に示す。

1) 排ガス中の CO および $\mathrm{NO}_{\mathrm{x}}$ 濃度は、圧力の依存性が明ら かであり、同じ $\mathrm{O}_{2}$ 濃度では、圧力が高いほどそれらの 濃度は低くなった。

2) 排ガス中の $\mathrm{N}_{2} \mathrm{O}$ 濃度は、燃焼炉内のフリーボード温度分 布が同等であれば、圧力が高くなるに連れて増加する傾 向にあるが、フリーボード温度に強い依存性を示す。

\section{謝辞}

本研究は、月島機械株式会社㧍よび三機工業株式会社と の共同研究に扔いて実施した成果の一部である。ここに記 して、謝意を表する。

\section{引用文献}

1）村上高広、鈴木善三、長沢英和、山本隆文、小関多賀美、廣瀬均、 


\section{研究室規模の加圧流動層燃焼炉による下水污泥の排ガス特性に及ぼす圧力の影響（村上・鈴木）}

岡本誠一郎 : 高温学会誌、35 (2009) 81-84.

2) 村上高広、鈴木善三、長沢英和、山本隆文、小関多賀美、廣瀬均、 落修一 : 高温学会誌、34 (2008) 166-170.

3) T. Murakami, S. Suzuki, H. Nagasawa, T. Yamamoto, T. Koseki, H. Hirose and S. Ochi : 3rd Intl. Symp. on Advanced Fluid/Solid Science and Technology in Experimental Mechanics, Taiwan (2008), paper number C3-4-57.

4) M. Sanger, J. Werther and T. Ogada : Fuel 80 (2002) 167-177.

5) J. R. Pels, M. A. Wojtowicz, F. Kapteijn and J. A. Moulijn : Energy \& Fuels 9 (1995) 743-752.

6) B. Leckner : Prog. Energy Combust. Sci. 24 (1998) 31-61.

7) B. Leckner, L. E. Amand, K. Lucke and J. Werther : Fuel 83 (2004)
477-486.

8) K. Svoboda and M. Pohorely : Fuel 83 (2004) 1095-1103.

9) A. T. Atimtay and B. Kaynak : Fuel Proc. Tech. 89 (2008) 183-197.

10) M. Shoji, T. Yamamoto, S. Tanno, H. Aoki and T. Miura : Energy 30 (2005) 337-345.

11) 鈴木善三、幡野博之、守富寛 : 日本エネルギー学会誌、84 (2005) 773-779.

12) T. Murakami, S. Suzuki, H. Nagasawa, T. Yamamoto, T. Koseki, H. Hirose and S. Okamoto : Fuel Proc. Tech. 90 (2009) 778-783.

13) T. Murakami, A. Kitajima, S. Suzuki, H. Nagasawa, T. Yamamoto, T. Koseki, H. Hirose and S. Okamoto : 20th Intl. Conf. on Fluidized Bed Combustion 2 (2009) 877-882. 